\title{
AUXÍLIO-RECLUSÃO: Análise do Benefício Previdenciário
}

http://dx.doi.org/10.21527/2176-6622.2021.55.20-33

Recebido em: 7/4/2020

Modificações solicitadas em: 12/8/2020

Aceito em: 7/9/2020

Antonio Paulo Guillen Hurtado

Autor correspondente. Faculdade Dom Bosco. Avenida XV de Novembro, no 57, Centro, Cornélio Procópio/PR, Brasil. CEP 86300-000. http://lattes.cnpq.br/8524523697834921. https://orcid.org/0000-0002-4908-7704. antoniopauloguillen.adv@hotmail.com

Carollyne Pereira da Costa Guerreiro

Faculdade Dom Bosco.

Cláudia Ramos de Souza Bonfim

Faculdade Dom Bosco.

\section{RESUMO}

O auxílio-reclusão é devido aos familiares dependentes do segurado da Previdência Social que se encontrar preso em regime fechado. Este estudo é de abordagem qualitativa, método dedutivo e caráter bibliográfico-jurídico-teórica. Fundamenta-se, especialmente, na Lei $n$. 8.213/91, que dispõe sobre os planos de benefícios da Previdência Social. O objetivo deste artigo é analisar a legislação previdenciária, mais precisamente no que diz respeito à Lei n. 8.213/91, demonstrando seus impactos na sociedade brasileira e as últimas alterações legislativas, assim como descrever a relevância do auxílio-reclusão por meio um levantamento dos valores que são pagos, e apresentar as mudanças legislativas que aconteceram ao longo dos anos. Questiona-se: Qual a importância social do auxílio-reclusão para a sociedade brasileira? Considera-se, ao final, que esse benefício é necessário para que muitas famílias não fiquem desamparadas, respeitando o princípio da dignidade da pessoa humana, conforme previsto na Constituição Federal de 1988.

Palavras-chave: Lei 8.213/91. MP 871/2019. Previdência social. Direito constitucional. Extinção do benefício.

\section{IMPRISONMENT AID: ANALYSIS OF THE SOCIAL SECURITY BENEFIT}

\section{ABSTRACT}

The imprisonment aid is owned to family members who are dependent on the Social Security insured who are in prison. This study has a qualitative approach, deductive reasoning and is bibliographic-legal-theoretical. It is based especially on Act $n=8.213 / 91$ which provides for Social Security benefit plans. The general objective of this paper is to analyze the social security legislation, more precisely with regarding to Act $n=8.213 / 91$, demonstrating its impacts on Brazilian society, and also the changes brought by MP 871/2019. And its specific objectives are to describe the importance of the prison aid to society, identify the technical aspects by conducting a survey of the amounts that are paid, and present the legislative changes that have happened over the years. Questioning: what is the social importance of the imprisonment aid for Brazilian society? At the end, it is considered that this benefit is necessary so that many families are not left helpless, respecting the principle of human dignity, as provided for in the Federal Constitution of 1988.

Keywords: Act 8.213/91. MP 871/2019. Social security. Constitutional right. Termination of benefit.

\section{SUMÁRIO}

1 Introdução. 2 Origem do auxílio-reclusão. 3 Princípios constitucionais que norteiam o auxílio-reclusão. 4 Aspectos legais. 5 Resultados e discussões. 6 Considerações finais. 7 Referências. 


\section{INTRODUÇÃO}

O auxílio-reclusão é antigo companheiro do ordenamento jurídico brasileiro. A primeira vez que se falou no benefício foi no ano de 1933, e, a partir daí, ele vem sofrendo inúmeras mudanças, consolidando-se ao longo do tempo. Atualmente, é um benefício devido aos familiares dependentes do apenado enquanto perdurar os efeitos da prisão em regime fechado.

Neste contexto, questiona-se: Qual a importância social do auxílio-reclusão para a sociedade brasileira?

Parte-se do preceito de que o auxílio-reclusão é fundamental para a sociedade brasileira, pois visa a garantir a assistência econômica da família do preso durante o período de reclusão, sendo este um amparo mínimo para que suas dignidades sejam preservadas.

Para tanto, o presente estudo tem como objetivo geral analisar a legislação previdenciária, mais precisamente no que se refere à Lei $n$ o 8.213/91, demonstrando seus impactos na sociedade brasileira, e também as mudanças trazidas pela MP 871/2019. São seus objetivos específicos: descrever a importância do auxílio-reclusão para a sociedade, identificar os aspectos técnicos, realizando um levantamento dos valores que são pagos, e apresentar as mudanças legislativas que aconteceram ao longo dos anos pertinentes ao tema. $O$ trabalho apresenta resultados e discussões a partir de levantamento de dados do Levantamento Nacional de Informações Penitenciárias (Infopen) baseado nas estatísticas do sistema penitenciário brasileiro referente aos estabelecimentos penais e à população encarcerada, considerando somente penitenciárias federais.

Justifica-se o tema porque grande parte da população não tem conhecimento de que para receber o benefício é necessário o preenchimento dos requisitos previstos em lei. Muitos conteúdos são apresentados por meio da internet com o intuito de manipular os cidadãos e induzir a uma visão equivocada sobre o benefício, sendo tratado como um incentivo ao crime quando, na verdade, refere-se a um benefício da Previdência Social que visa a proteger a família do cidadão que é contribuinte, e que, porventura, cometeu algum delito e foi preso. Deseja-se oportunizar conhecimento sobre esta área do Direito Previdenciário brasileiro, instruindo com informações relevantes e trazendo o Direito mais próximo da vida das pessoas.

A pesquisa é de abordagem qualitativa, método dedutivo e caráter bibliográfico-jurídico-teórica, com referencial embasado em artigos publicados em Revistas Científicas, livros, leis e jurisprudências que abordam o tema.

O método é dedutivo, pois parte-se de uma premissa existente, um fato, um conhecimento prévio geral e busca-se demonstrá-la ao longo do estudo, para, de maneira lógica, por meio de argumentações conceituais, chegar a uma verdade, a uma conclusão.

Ainda que baseada em alguns dados quantitativos, a abordagem é qualitativa, pois, segundo Minayo (2001, p. 21), a pesquisa qualitativa

[...] se preocupa, nas ciências sociais, com um nível de realidade que não pode ser quantificado. Ou seja, ela trabalha com um universo de significados, motivos, aspirações, crenças, valores e atitudes, o que corresponde a um espaço mais profundo das relações, dos processos e dos fenômenos que não podem ser reduzidos à operacionalização das variáveis.

A partir deste estudo será possível comprender, de forma mais aprofundada, os fundamentos do auxílio-reclusão, abrindo caminhos para construir novos olhares e debates sobre o assunto.

Nos capítulos a seguir apresentam-se a origem do benefício e como foi sua criação no Brasil, alguns princípios constitucionais que fundamentam o benefício do auxílio-reclusão e os aspectos legais que envolvem o benefício, trazendo, em ordem cronológica, as alterações legislativas ao longo dos anos, com ênfase na MP 871/2019. Os resultados e discussões também levam em consideração uma análise de dados do Infopen, que é um sistema de informações estatísticas do sistema penitenciário brasileiro.

\section{ORIGEM DO AUXÍLIO-RECLUSÃO}

Ao contrário do que se pensa, o benefício não foi criado recentemente, pois o auxílio-reclusão estreou no ordenamento jurídico brasileiro em junho de 1933 pelo extinto Decreto n. 22.872, que criou o Instituto de Aposentadoria e Pensões dos Marítimos, que, em seu artigo 63, mais especificamente no seu parágrafo único, tratava do referido benefício. 
Logo no ano seguinte foi criado o Decreto n. 54/34, que aprovava e regulamentava o Instituto de Aposentadoria e Pensão dos Bancários (IAPB), que, em seu artigo 67, trazia a previsão de um benefício quando um de seus associados se encontrasse preso.

No ano de 1960, apesar de já existir para algumas categorias de trabalhadores, o benefício generaliza-se por meio da Lei n. 3.807, Lei Orgânica da Previdência Social (Lops), sendo vinculado a algumas condições, dentre elas a contribuição prévia, mas mantendo seu status de seguro social (LIMA NETA, 2017).

Em 1988, com a chegada da Constituição da República Federativa do Brasil, aconteceu um marco jurídico-político, pois, a partir daí, o auxílio-reclusão passou a ser disciplinado expressamente na legislação constitucional. Pela redação, que já fora modificada, no artigo 201, inciso I, o qual estabelecia que os planos de Previdência Social deveriam cobrir os riscos sociais resultantes da prisão de qualquer pessoa que fosse contribuinte, não existindo ainda critérios rígidos para concessão do benefício, passou a ser não apenas um direito legal, mas um direito constitucional.

Em seguida, a Lei n. 8.213, de 24 de junho de 1991, que trata dos Planos de Benefícios da Previdência Social, trazia alguns requisitos, em seu artigo 80 , que tinha a seguinte redação:

Art. 80. O auxílio-reclusão será devido, nas mesmas condições da pensão por morte, aos dependentes do segurado recolhido à prisão, que não receber remuneração da empresa nem estiver em gozo de auxílio-doença, de aposentadoria ou de abono de permanência em serviço.

Parágrafo único. O requerimento do auxílio-reclusão deverá ser instruído com certidão do efetivo recolhimento à prisão, sendo obrigatória, para a manutenção do benefício, a apresentação de declaração de permanência na condição de presidiário (BRASIL, 1991).

A Emenda Constitucional n. 20/1998, que alterou o artigo 201, I da CF/88, trouxe mais um requisito de seletividade para a concessão do auxílio-reclusão, fazendo com que houvesse diversas controvérsias sobre o tema, pois instituiu o critério de baixa-renda, dificultando para que os dependentes do recluso pudessem receber a prestação previdênciária, o que fez com que muitos doutrinadores, como Hélio Gustavo Alves (2007), Fábio Zambitte Ibrahim (2008) e Eduardo Rocha Dias e José Leandro Monteiro de Macedo (2010), criticassem, pois estaria distorcendo a real finalidade do benefício, que seria prover as necessidades básicas da família do preso.

Art. 201. A previdência social será organizada sob a forma de regime geral, de caráter contributivo e de filiação obrigatória, observados critérios que preservem o equilíbrio financeiro e atuarial, e atenderá, nos termos da lei, a: [...]

IV - Salário-família e auxílio-reclusão para os dependentes dos segurados de baixa renda; (BRASIL, 1998).

No ano de 1999 foi editado o Decreto no 3.048, regulando a Previdência Social e trazendo vários outros critérios dispostos nos artigos 116 ao 119, dentre eles a preexistência de dependência econômica e a apresentação trimestral de atestado de que o segurado continua preso. Em 2003, o Decreto no 4.729 alterou o $\S$ 4 ㅇ e incluiu os parágrafos $\S 5$ e $\S 6$, que instituíram os tipos de prisão em que o segurado poderia receber 0 auxílio e também que a atividade remunerada realizada pelo recluso não faria com que os beneficiários perdessem o auxílio-reclusão, desde que continuasse contribuindo.

§ 50 O auxílio-reclusão é devido, apenas, durante o período em que o segurado estiver recolhido à prisão sob regime fechado ou semi-aberto. (Incluído pelo Decreto no 4.729, de 2003).

$\S 6$ o 0 exercício de atividade remunerada pelo segurado recluso em cumprimento de pena em regime fechado ou semi-aberto que contribuir na condição de segurado de que trata a alínea "o" do inciso V do art. 9o ou do inciso IX do $\S 1$ o do art. 11 não acarreta perda do direito ao recebimento do auxílio-reclusão pelos seus dependentes (Incluído pelo Decreto oㅜ 4.729, de 2003) (BRASIL, 2003).

Em janeiro de 2019, assim que o presidente Jair Bolsonaro assumiu a presidência da República, ele editou a Medida Provisória no 871 alterando a Lei no 8.213/91 e trazendo novos critérios mais rigorosos. Tais critérios de seletividade entram em conflito com os princípios constitucionais que regem o auxílio-reclusão (ARAÚJO, 2012). 


\section{PRINCÍPIOS CONSTITUCIONAIS QUE NORTEIAM O AUXÍLIO-RECLUSÃO}

As leis brasileiras são embasadas em princípios que buscam, principalmente, igualdade social e justiça. Sendo assim, destaca-se alguns princípios constitucionais que fundamentam o benefício auxílio-reclusão, como o princípio da dignidade da pessoa humana, princípios da proteção familiar, princípio da erradicação da pobreza e o princípio da solidariedade social.

No Princípio da Dignidade da Pessoa Humana, de acordo com Piovesan (2000), a dignidade da pessoa é um dos mais relevantes princípios estabelecidos na Constituição, estando ao lado dos Direitos e Garantias Fundamentais, agregando valores éticos e de justiça dentro do ordenamento jurídico brasileiro.

A Dignidade da Pessoa Humana está consagrada na CF/88, em seu artigo 10, inciso III (BRASIL, 2019h), posto que este princípio busca uma sociedade igualitária, na qual todos os seus integrantes se desenvolvam plenamente, sendo aí que o Estado entra por meio de prestações positivas dando assistência às pessoas, pois é seu dever manter condições mínimas para que um indivíduo viva em sociedade, particularmente aos que não têm condições de se sustentar, que é o caso quando o pai ou a mãe de família se encontra preso. O príncipio em questão busca o desenvolvimento social e os valores de liberdade, paz e justiça (ARAÚJO, 2012).

Uma pessoa ser presa, por qualquer motivo que seja, não afastará dela o princípio da dignidade humana, que nunca pode ser retirado de ninguém, uma vez que é intríseco ao ser humano, não sendo possível, por motivo algum, afastá-lo.

O Princípio da Proteção Familiar traz que a família deve ser protegida pelo Estado. De acordo com o artigo 226, caput, da CF/88, "a família, base da sociedade, tem especial proteção do Estado", proteção essa que independe da sua situação ou composição familiar. Este princípio justifica plenamente a concessão do benefício do auxílio-reclusão, uma vez que os dependentes do segurado necessitam mais ainda deste amparo. Segundo a $\mathrm{CF} / 88$, em seu artigo 227,

Art. 227. É dever da família, da sociedade e do Estado assegurar à criança, ao adolescente e ao jovem, com absoluta prioridade, o direito à vida, à saúde, à alimentação, à educação, ao lazer, à profissionalização, à cultura, à dignidade, ao respeito, à liberdade e à convivência familiar e comunitária, além de colocá-los a salvo de toda forma de negligência, discriminação, exploração, violência, crueldade e opressão (Redação dada Pela Emenda Constitucional no 65, de 2010) (BRASIL, 2019).

Como uma família que teve seu provedor preso conseguirá, sem o amparo do Estado, assegurar aos seus dependentes os direitos previsto no artigo mencionado? Por isso o auxílio-reclusão visa a proteger a família e desenvolver, ao máximo, seus membros, uma vez que a família é indispensável para a formação do ser humano.

O Princípio da Erradicação da Pobreza está previsto no artigo 3으, inciso III, da CF/88, que descreve "constituem objetivos fundamentais da República Federativa do Brasil: [...] III - erradicar a pobreza e a marginalização e reduzir as desigualdades sociais e regionais" (BRASIL, 2019h).

Vale ressaltar que a desigualdade social e a marginalização acarretam maiores chances do envolvimento com a delinquência, podendo o familiar que ficou desamparado ocorrer em crimes para sua subsistência ou se envolver com drogas, posto que quem mantinha a família não mais pode fazer. Desse modo, o amparo do Estado se faz indispensável, uma vez que ninguém que tenha o mínimo de compaixão para com o próximo deseje que o restante da família siga o mesmo caminho de quem foi preso (ARAÚJO, 2012).

Sendo assim, o auxílio-reclusão vem para concretizar o princípio da erradicação da pobreza, haja vista que o benefício, apesar de não ser voluptuoso, vai garantir o mínimo de subsistência, evitando, assim, a pobreza da família, nos casos em que a única fonte de renda era por meio do segurado que foi preso.

De acordo com o Princípio da Solidariedade Social, previsto no artigo 3ㅇ, inciso I, da CF/88, "constituem objetivos fundamentais da República Federativa do Brasil: I - Construir uma sociedade livre, justa e solidária [...]" (BRASIL, 2019h). A Solidaridedade Social resume-se em ações que fortalecem uma sociedade em conjunto. A CF/88 traz, em seu artigo 194, uma justificativa para a existência do auxílio-reclusão, sendo obrigação do Estado aplicar a solidariedade para assegurar uma sociedade mais justa para os desprotegidos. 
Quando, portanto, o beneficiário encontra-se preso, a assistência para sua família reflete a cooperação da maioria, contribuindo para a subsistência da minoria, de acordo com a capacidade contributiva. $\mathrm{O}$ auxílio-reclusão visa à proteção social e tem caráter assistencial, sendo encargo do Estado (ARAÚJO, 2012).

Nessa perspectiva, o auxílio-reclusão contribui com o direito ao desenvolvimento, voltado, principalmente, no que se refere à sua dimensão social e jurídico-política. Em relação à dimensão social, busca a promoção da qualidade de vida do indivíduo, garantindo o mínimo essencial para o seu bem-estar. Ainda nesse sentido, a dimensão jurídico-política busca o desenvolvimento dos direitos fundamentais, respeitando a dignidade da pessoa, os direitos humanos e a distribuição de renda de forma adequada (GOMES; FERREIRA, 2018).

Dessa forma, sempre deve prevalecer o interesse da coletividade e não o da individualidade, pois a proteção social e a dignidade da pessoas humana estão acima de qualquer interesse particular.

O capítulo seguinte versa sobre os aspectos legais que envolvem o benefício, trazendo, em ordem cronológica, as alterações legislativas ao longo dos anos, com ênfase na MP 871/2019 (BRASIL, 2019c).

\section{ASPECTOS LEGAIS}

Ainda que no Brasil as prisões estejam superlotadas, não são todos os presos que recebem o auxílio-reclusão, considerando que a maioria não preenche os requisitos necessários para a concessão do benefício, sendo concedido apenas para uma parcela minoritária dos reclusos. É notório, no entanto, que notícias falsas são divulgadas nas mídias, fazendo com que muitas pessoas repudiem o benefício por falta de conhecimento. O auxílio-reclusão não é um presente do governo para quem comete crimes, mas, sim, um direito constitucional do cidadão que trabalha com carteira assinada e contribui com a Previdência Social (ROQUE, 2015).

Segundo Hélio Gustavo Alves (2007),

[...] o sistema carcerário tem como função reeducar o preso e uma das formas de ressocialização é dar-lhe oportunidade de exercer uma atividade profissional dentro do sistema carcerário, fato que não ocorre. Logo, o preso, além de não estar sendo reeducado, por uma falha no sistema não pode exercer qualquer espécie de trabalho, primeiro por estar recluso, segundo por má administração do Estado em não construir uma penitenciária produtiva que proporcione o exercício profissional (p. 35).

Por falha do Estado em não conceder condições mínimas para os presos trabalharem dentro dos presídios, as famílias destes não podem ficar desamparadas, uma vez que elas não cometeram crime algum, e não devem pagar, portanto, pelo delito juntamente com a pessoa que foi presa. Esse benefício tem o intuito de beneficiar as famílias dos reclusos que possuem dependência financeira, não podendo ficar desamparadas, sendo-lhes garantindo o mínimo essencial para sobreviverem na ausência do familiar preso.

O referido autor nos ensina, ainda, que

[...] o auxílio-reclusão é um benefício que garante a proteção da família e dependentes, além da fundamental importância para o equilíbrio da economia do País, ou seja, proporciona aos recebedores uma qualidade de vida digna, servindo a renda mensal para sustentação às bases alimentar e educacional e à saúde (ALVES, 2007, p. 16).

No ano de 2013 tramitou no Congresso Nacional a PEC 304/2013 (BRASIL, 2013a) com o objetivo de extinguir o auxílio-reclusão, substituindo o mesmo por um auxílio às vítimas. A deputada Antônia Lúcia (PSC-AC), em uma entrevista ao site da Câmara dos Deputados, publicada em 22/1/2014, justificou tal projeto de Emenda Constitucional afirmando que "hoje não há previsão de amparo para vítimas do criminoso e suas famílias", o que não é verdade, posto que, se a vítima também for contribuinte da Previdência Social, receberá o benefício adequado caso preencha os requisitos exigidos (BRASIL, 1991).

A PEC 304/2013 aguarda parecer do relator da Comissão de Constituição e Justiça e de Cidadania (CCJC).

Nesse mesmo sentido, tramitou o Projeto de Lei n. 5.671/2013 (BRASIL, 2013b), de autoria do deputado André Moura (PSC-SE), que visava a alterar o artigo 80 da Lei 8.213/91 para que o auxílio-reclusão fosse rateado entre os dependentes das vítimas de homicídio. Em apenso a este Projeto de Lei, também tramitou no Congresso Nacional o PL 8.313/14, de autoria do deputado federal Diego Andrade (PSD-MG), que tinha o intuito de destinar integralmente o valor do auxílio-reclusão à família da vítima, nos casos de homicídio consumado ou tentado e nos casos em que ocorrer sequelas irreversíveis à vítima (BRASIL, 2015). 
Os dois Projetos de Lei supracitados foram arquivados no dia 13/12/2018 pelo plenário da Câmara dos Deputados, tendo em vista que o parecer do Relator deputado federal Diego Garcia, na Comissão de Seguridade Social e Família (CSSF), rejeitou o PL 5.671/2013 e todos os outros que a este estavam apensados, sob os argumentos de que, primeiramente, não é possível que lei ordinária como tais projetos altere um direito garantido constitucionalmente, pois o benefício do auxílio-reclusão está expressamente descrito no artigo 201, IV da CRFB/88 (BRASIL, 2019), quando a Constituição garantiu esse benefício aos dependentes do segurando e não deu margem para que lei pudesse estabelecer destinação diversa, podendo, assim, somente por meio de proposta de emenda à Constituição, destinar o benefício às vítimas e não aos dependentes do segurado.

Outro ponto em relação ao mérito destacado pelo relator na CSSF, é que o titular do benefício não é o preso, e, sim, seus dependentes, que, com o auxílio-reclusão, têm uma forma de manter o sustento da família em razão de o segurado estar impossibilitado de trabalhar, uma vez que se encontra preso. O auxílio-reclusão tem caráter contributivo, portanto não se trata de uma escolha de o Estado conceder ou não o benefício, pois as pessoas que contribuírem e estiverem dentro das exigências estabelecidas na lei vão ter o direito ao auxílio-reclusão (BRASIL, 2018c).

Não se sustenta o argumento de que as famílias das vítimas ficam desamparadas pelo governo, pois se a vítima também contribuir para a Previdência Social, seus dependentes terão direito aos benefícios previdenciários que lhe cabem. Caso uma vítima que seja segurada do INSS venha a sofrer uma lesão corporal, por exemplo, terá direito ao auxílio-doença se ficar incapacitado para o trabalho; no caso de vítima de homicídio, os dependentes terão direito à pensão por morte (BRASIL, 1991). No âmbito do Direito Civil, a família da vítima pode buscar reparação pelos danos materiais e morais causados por quem cometeu o crime (BRASIL, 2019a).

No dia 18 de janeiro de 2019 entrou em vigor a Medida Provisória no 871/2019, alterando a Lei no $8.213 / 91$, trazendo critérios mais exigentes, fazendo com que esses critérios entrassem em conflito com os princípios constitucionais, limitando, assim, sua verdadeira função, que é dar suporte aos dependentes do segurado recluso que não tem condições de sobreviver sem a renda antes auferida pelo beneficiário (ARAÚJO, 2012).

O benefício era concedido às famílias que cumpriam com os requisitos sem nenhuma exigência de tempo mínimo de contribuição, porém, atualmente, é exigida a carência de 24 meses de contribuições, ou seja, que tenha contribuído 2 anos de forma ininterrupta (BRASIL, 2019).

Outra mudança trazida no artigo 80 da Lei $n^{\circ} 8.213 / 91$ foi a impossibilidade de a família de presos que se encontram em regime semiaberto receber o benefício, pois somente as famílias que possuem presos no regime fechado poderão receber o auxílio-reclusão. Os beneficiários do regime semiaberto que garantiram seu direito antes da MP 871/19, entretanto, continuarão recebendo normalmente (BRASIL, 2019).

O § 40 do artigo 80 da Lei $n^{\circ} 8.213 / 91$, ainda trouxe alteração no cálculo do salário para determinar se o segurado é de baixa renda ou não. Antes era observado apenas o último salário, no entanto agora é feita a média dos últimos 12 salários de contribuição (BRASIL, 2019).

Também é necessária a certidão judicial chamada declaração de cárcere para instruir o pedido de concessão do benefício, que é uma certidão emitida pela unidade prisional em que se encontra o preso, sendo obrigatória para sua manutenção, devendo ser apresentada de três em três meses (BRASIL, 2019).

Havendo perda da qualidade de segurado, o mesmo terá de, após a perda, computar um novo período de carência para fazer jus aos benefícios de auxílio-doença, salário maternidade e auxílio-reclusão. De acordo com a medida provisória, era necessário contar novamente o mesmo período integral, mas, com a entrada em vigor da Lei no 13.846/2019, basta o segurado cumprir metade do tempo de carência para recuperar a qualidade de segurado.

Em seu artigo 59, § 2ㅇ, a MP incluiu a impossibilidade de o preso em regime fechado receber auxílio-doença, e se o contribuinte estiver em gozo do auxílio-doença este ficará automaticamente suspenso com o recolhimento à prisão (BRASIL, 2019).

O auxílio-reclusão foi criado há mais de 50 anos e foi recepcionado pela CF/88, que preza, acima de tudo, pelo princípio da dignidade da pessoa humana. Sendo assim, a legislação previdenciária que trata dos benefícios da Previdência Social, Lei n. 8.213/91, estabeleceu que o auxílio-reclusão será devido aos depen- 
dentes do segurado recolhido à prisão que não estiver recebendo nenhuma remuneração da empresa, nem esteja em gozo do auxílio-doença, pensão por morte, aposentadoria, salário-maternidade ou abono de permanência, sendo ele ofertado seguindo algumas condições da pensão por morte, devendo ser observado o artigo 25 , IV.

Neste sentido, Fábio Zambitte Ibrahim (2008) destaca:

Caso o segurado sofra um acidente ou preencha os requisitos para a aposentadoria, não poderá cumular os benefícios decorrentes destes eventos com o auxílio-reclusão, recebido por seus dependentes. Todavia, se o novo benefício for superior ao auxílio reclusão, poderá haver a opção por aquele. Naturalmente, tratando-se de auxílio-doença e existindo a percepção do mesmo (em razão de opção do segurado), quando da consolidação futura das lesões, o auxílio-doença extinguir-se-á e voltará a ser pago o auxílio-reclusão (p. 600).

A Emenda Constitucional n. 20/98 alterou o inciso IV, artigo 201, da Constituição Federal, determinando que o benefício seja concedido aos dependentes de baixa renda e fixado em três salários de contribuição, e esta situação financeira deve ser constatada no momento em que o indivíduo for preso.

O Ministério da Economia publicou no Diário Oficial da União, no dia 15 de janeiro de 2019, a Portaria n. 09/2019, mostrando que deverão ser considerados de baixa renda, e, portanto, receber o auxílio-reclusão, os dependentes do segurado que teve o salário de contribuição inferior ou igual a $R \$ 1.364,43$.

A mudança trazida pela EC n. 20/98, entretanto, levou a muitas discussões entre vários autores acerca da sua constitucionalidade, pois o segurado que estivesse contribuindo teria direito adquirido sobre o auxílio, e a EC n. 20/98 não estaria respeitando a igualdade conquistada, conforme esclarece Hélio Gustavo Alves (2007):

[...] a igualdade é um direito fundamental; mais ainda, é um princípio universal estampado na Declaração Universal e em inúmeros tratados, com o principal objetivo de igualar os privilegiados com os desprivilegiados para estes terem os mesmos direitos, deveres e garantias fundamentais, não podendo uma norma (Emenda 20/98) adentrar a Carta Magna por meio de Emenda, para desestruturar o alicerce dos direitos fundamentais (p. 118).

Da mesma forma, explica Fábio Zambitte Ibrahim (2008):

A alteração constitucional foi de extrema infelicidade, pois exclui a proteção de diversos dependentes, cujos segurados estão fora do limite de baixa renda. Esta distinção, para o auxílio-reclusão, não tem razão de ser, pois tais dependentes poderão enfrentar situação difícil, com a perda da remuneração do segurado (p. 598).

Outros autores também defendem que teria de ser constatada a baixa renda do dependente que fosse receber o auxílio e não do recluso.

Dias e Macedo (2010), então, afirmam:

Neste tipo de benefício não dá para fazer a seleção dos beneficiários levando-se em conta a renda do recluso. Qualquer que seja essa renda, dentro do limite de proteção do Regime Geral de Previdência Social, a reclusão causará inexoravelmente o estado de necessidade para as pessoas que dele dependiam economicamente (p. 280).

Há de se pensar no fato de que os dependentes do segurado que recebem valor superior ao permitido para fazer jus ao benefício, poderiam passar por necessidades caso o provedor de sua família venha ser preso. A EC n. 20/98 deixou essas pessoas desprotegidas. Coadunante a este pensamento, Alves (2007) ainda ensina:

Qual a diferença do cidadão que contribui menos para o que contribui mais? (exceto a base de cálculo) Qual a diferença entre aquele que tem uma renda menor ou maior, se ambos serão ou estão presos, sem poder exercer de igual forma as suas profissões sendo que tanto o "pobre" quanto o "rico" deixarão de sustentar suas famílias pelo mesmo motivo, ou seja, a prisão? (p. 93).

Para Alves (apud SILVA; ANDRADE, 2014), a EC n. 20/98 é inconstitucional, pois o auxílio-reclusão tem como objetivo a proteção dos dependentes que ficarão desamparados com a reclusão do segurado, sendo injusta a constatação da baixa renda do segurado e não sendo analisadas as reais condições dos dependentes. 
O Decreto n. 3.048/99 trata especificamente das regras de concessão do auxílio-reclusão, sendo o primeiro critério para sua concessão a prisão do segurado, conforme o artigo 166: "[...] § 2 @ O pedido de auxílio-reclusão deve ser instruído com certidão do efetivo recolhimento do segurado à prisão, firmada pela autoridade competente" (BRASIL, 1999).

Para o dependente requerer o pagamento do auxílio-reclusão, este deverá solicitar diretamente no INSS com horário previamente agendado. Ele necessita, primeiramente, acessar o portal "Meu INSS", fazer o cadastro, logo após clicar na opção agendamentos e comparecer à unidade do INSS no dia marcado munido dos documentos solicitados, sendo possível, também, o agendamento pelo telefone 135 (BRASIL, 2017).

Os documentos indispensáveis para requerer o benefício são o documento com foto do interessado no auxílio, dos dependentes e do preso, documentos que comprovem os 24 meses de contribuições do recluso, como os carnês de contribuição individual e a carteira de trabalho, documento que comprove a dependência econômica nos casos em que ela é exigida e, por fim, a declaração do cárcere (BRASIL, 2017).

A declaração de cárcere é um documento fornecido pela unidade prisional onde o segurado se encontra preso, como já mencionado. Para manutenção do benefício é necessária a apresentação desta declaração de três em três meses junto ao INSS, mas, em relação à declaração de cárcere, a mudança trazida pela MP 871/19 mostra que será instituído um convênio entre o INSS e a Justiça. Como, entretanto, a mudança é recente, o INSS ainda não emitiu orientações, devendo os dependentes continuar levando a declaração de cárcere até que essa parceria do INSS com a Justiça esteja plenamente funcionando (BRASIL, 2017).

A Emenda Constitucional 103/2019, em seu artigo 27, § 1으, traz que o valor a ser pago de auxílio-reclusão não excederá um salário mínimo, e seu cálculo será realizado na forma aplicável à pensão por morte. Se o segurado iniciou suas contribuições antes do ano de 1999, somente serão levadas em conta as contribuições a partir do ano de 1994. Se o segurando começou a contribuir após 1999 serão consideradas, no cálculo, todas as suas contribuições. Assim dispõe o artigo 188-A do Decreto n. 3.048/99:

Art. 188-A. Para o segurado filiado à previdência social até 28 de novembro de 1999, inclusive o oriundo de regime próprio de previdência social, que vier a cumprir as condições exigidas para a concessão dos benefícios do Regime Geral de Previdência Social, no cálculo do salário-de-benefício será considerada a média aritmética simples dos maiores salários-de-contribuição, correspondentes a, no mínimo, oitenta por cento de todo o período contributivo decorrido desde a competência julho de 1994, observado o disposto nos incisos I e II do caput e $\S 14$ do art. 32 (Incluído pelo Decreto no 3.265, de 1999) (BRASIL, 1999).

Vale lembrar que o auxílio-reclusão nunca será inferior ao valor do salário mínimo nacional, independentemente do valor que se encontrou nesses cálculos, de acordo com artigo 32, § 3으, do Decreto n. 3.048/99: "§3으 O valor do salário-de-benefício não será inferior ao de um salário mínimo, nem superior ao limite máximo do salário-de-contribuição na data de início do benefício" (BRASIL, 1999).

O benefício será devido a partir do recolhimento do segurado à prisão, se este for requerido até 30 dias. Se for requerido após 30 dias da prisão será devido a partir da data do requerimento, conforme está disposto no artigo 116, § 4으, do Decreto no 3.048/99:

$\S 4$ ㅇ A data de início do benefício será fixada na data do efetivo recolhimento do segurado à prisão, se requerido até trinta dias depois desta, ou na data do requerimento, se posterior, observado, no que couber, o disposto no inciso I do art. 105 (Redação dada pelo Decreto no 4.729, de 2003) (BRASIL, 1999).

Em relação à duração do benefício, ele varia de acordo com a idade dos dependentes e o tipo de beneficiário. Será de 4 meses contados a partir da data da reclusão se a prisão ocorrer sem que o segurado tenha completado 18 contribuições à Previdência Social, ou se a união estável ou o casamento tenha ocorrido em menos de 2 anos antes da prisão do segurado.

Se a prisão se deu após 18 contribuições mensais e o casamento ou união estável tenha acontecido pelo menos 2 anos antes, a duração do auxílio-reclusão será variável conforme o Quadro a seguir. 
Quadro 1 - Duração do auxílio-reclusão

\begin{tabular}{|c|c|}
\hline Idade do dependente da data da prisão & Duração máxima do benefício ou cota \\
\hline Menos de 21 anos & 3 anos \\
\hline Entre 21 e 26 anos & 6 anos \\
\hline Entre 27 e 29 anos & 10 anos \\
\hline Entre 30 e 40 anos & 15 anos \\
\hline Entre 41 e 43 anos & 20 anos \\
\hline A partir de 44 anos & Vitalício \\
\hline
\end{tabular}

Fonte: BRASIL (2017).

O benefício cessa ao completarem 21 anos para os filhos ou equiparados, exceto se for inválido ou deficiente. Se houver emancipação, haverá a cessação do benefício (BRASIL, 2017).

Caso o segurado seja posto em liberdade, o dependente ou responsável deve apresentar imediatamente ao INSS o alvará de soltura, assim cessará também o auxílio; portanto, só é devido quando estiver recluso em regime fechado, devendo o beneficiário apresentar atestado trimestralmente dado por autoridade competente, alegando que o segurado continua recluso conforme o Decreto no 3.048/99.

Há casos em que o benefício pode ser suspenso, conforme explica o artigo 395 da Instrução Normativa no 77 de 21 de janeiro de 2015 :

Art. 395. Os pagamentos do auxílio-reclusão serão suspensos:

I - na hipótese da opção pelo auxílio-doença, na forma do §20 do art. 383;

II - se o dependente deixar de apresentar atestado trimestral, firmado pela autoridade competente, para prova de que o segurado permanece recolhido à prisão; e

III - se o segurado recluso possuir, mesmo que nesta condição, vínculo empregatício de trabalho empregado, doméstico ou avulso (BRASIL, 2015).

O benefício será restabelecido no dia posterior ao término do auxílio-doença ou no dia seguinte após o encerramento do vínculo empregatício. Há casos, entretanto, em que ocorrerá a extinção do benefício, como explica Horvath Jr. (2014):

Extinção do benefício: Extinção da última cota individual; Concessão da aposentadoria no período de privação da liberdade; Óbito do segurado; Soltura do preso; Emancipação ou atingimento de 21 anos para os filhos e irmãos, salvo se inválidos; Cessação da invalidez para dependentes inválidos (p. 415).

Nos casos de óbito, este pode ser do segurado ou do beneficiário. Nos casos de morte do segurado durante a reclusão, o benefício será automaticamente convertido em pensão por morte, segundo o artigo 118 do Decreto n. 3.048/99 (BRASIL, 1999).

Em relação à alínea "e", do mesmo artigo, nos casos dos filhos ou irmãos, o benefício também cessará caso haja casamento, início de emprego público efetivo ou, ainda, constituição de estabelecimento comercial ou relação de emprego, desde que, em razão destes, o menor com 16 anos completos tenha economia própria.

A Instrução Normativa n. 77/2015 apresenta outras hipóteses de cessação do benefício em seu artigo 394, conforme se exposto a seguir:

Art. 394. O auxílio-reclusão cessa: [...]

VII - pela adoção, para o filho adotado que receba auxílio reclusão dos pais biológicos, exceto quando o cônjuge ou o companheiro (a) adota o filho do outro;

VIII - pelo levantamento da interdição no caso do (a) filho (a) ou irmã (o) com deficiência intelectual ou mental;

IX - pela fuga do recluso; e

$X$ - quando o segurado deixar a prisão por livramento condicional ou por cumprimento da pena em regime aberto (BRASIL, 2015). 
Nos casos de fuga, livramento condicional ou cumprimento de pena em regime aberto ou semiaberto, o benefício não poderá ser reativado; se houver a captura ou regressão de regime será considerado um novo fato gerador para requerimento do auxílio-reclusão, conforme dispõe o parágrafo único do artigo 394 da Instrução Normativa n. 77/2015 (BRASIL, 2015).

Conforme, portanto, disposto no $\S 20$ do artigo 395 da Instrução Normativa n. 77/2015, se no período em que o segurado fugiu ou estava em cumprimento de pena em regime aberto, ou estava em livramento condicional, tiver exercício de atividade remunerada que contribua para o INSS, este período será considerado para verificar a manutenção ou não da qualidade de segurado.

\section{RESULTADOS E DISCUSSÕES}

Foram analisados alguns dados extraídos do Infopen, que, segundo o site do Ministério da Justiça, são informações estatísticas do sistema penitenciário brasileiro. Este sistema é atualizado pelos gestores dos estabelecimentos prisionais desde 2004 e "sintetiza informações sobre os estabelecimentos penais e a população prisional" (BRASIL, 2019e).

O Infopen apresenta dados somente do Sistema Penitenciário Federal (SPF), que é composto por cinco penitenciárias, sendo elas Catanduvas/PR, Campo Grande/MS, Mossoró/RN, Porto Velho/RO e Brasília/DF. O estudo abarca, entretanto, somente quatro delas, pois a de Brasília foi inaugurada somente em 2018 e os dados são de 2016. Cada penitenciária federal possui capacidade para alojar 208 internos em celas individuais (BRASIL, 2016).

No SPF, em dezembro de 2016, o número de internos era de 472; já em 30 de junho de 2017 possuía 570 internos, distribuídos da seguinte maneira: 127 presos em Mossoró, 150 presos em Porto Velho, 143 presos em Campo Grande e 150 presos em Catanduvas. A idade predominante no SPF está na faixa de 28 a 39 anos, que corresponde a $63,01 \%$ do total.

Tratando-se da renda mensal, $52,70 \%$ dos presos possuem renda familiar abaixo de um salário mínimo e 92,90\% informaram possuir um ou mais filhos (BRASIL, 2016).

Em relação ao recebimento do auxílio-reclusão pode-se observar, no Gráfico a seguir, que apenas 8,33\% dos presos responderam que seus dependentes recebiam o benefício, o que faz constatar que houve uma queda, uma vez que no ano de 2015 esse percentual era de 11,15\%.

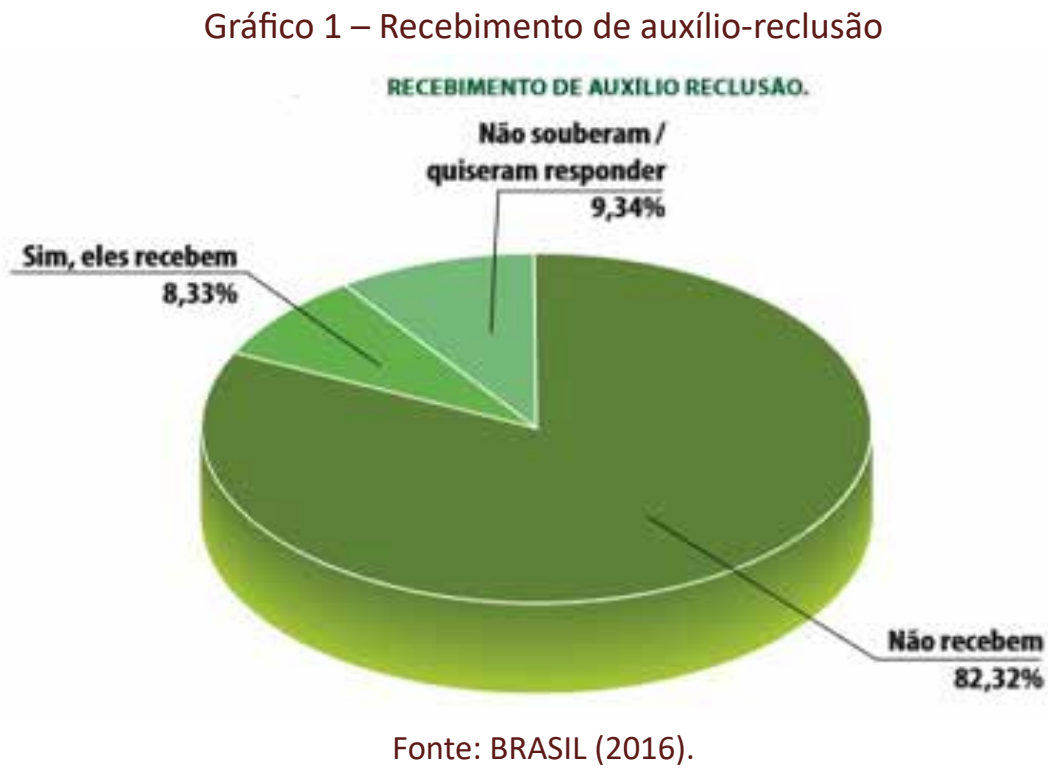

Apesar de os dados não serem recentes, é inegável que o auxílio-reclusão é um benefício restrito, divergente da ideia presente no imaginário social e divulgado erroneamente de que todos os presos e seus dependentes têm acesso ao benefício. Os estudos realizados pelo Ministério da Justiça demonstram claramente que a quantidade de presos em penitenciárias federais em que os dependentes recebem auxílio-reclusão não chega a $10 \%$ do total. 
Em matéria escrita pela jornalista Giuliana Saringer, veiculada pelo Portal R7 Notícias em 11/6/2018, com dados extraídos via Lei de Acesso à Informação, foi publicado que o INSS pagou 48.755 benefícios de auxílio-reclusão em abril/2018, e, desse total, 82\% foram pagos a dependentes com até 19 anos (SARINGER, 2018). Em agosto de 2018 o Conselho Nacional de Justiça (CNJ) divulgou o novo relatório do Banco Nacional de Monitoramento de Prisões (BNMP), apontando que havia 602.217 pessoas encarceradas no Brasil (BRASIL, 2018a).

Fazendo um paralelo, comparando os benefícios de auxílio-reclusão pagos em abril/2018 e a quantidade de presos divulgados em agosto/2018, constata-se que apenas $8,09 \%$ de todos os reclusos do país recebem o benefício, demonstrando que os dados divulgados pelo Infopen/2016, que abarca somente prisões federais, se repetem também no âmbito de todas as prisões nacionais. Destaca-se, portanto, mais uma vez, que o benefício não é concedido de qualquer maneira a qualquer recluso, senão estes números seriam consideravelmente maiores. Nota-se, no entanto, como são rígidos os critérios para concessão, pois somente aqueles que realmente cumprem os requisitos é que conseguem receber o benefício.

Outro aspecto importante é em relação a quem está recebendo o auxílio-reclusão como dependente. De acordo com o gráfico a seguir, divulgado no Informe de Previdência Social (LIMA NETA, 2017), 87\% dos benefícios são pagos aos filhos do recluso.

Gráfico 2 - Distribuição percentual de auxílios-reclusão concedidos por vínculo do dependente

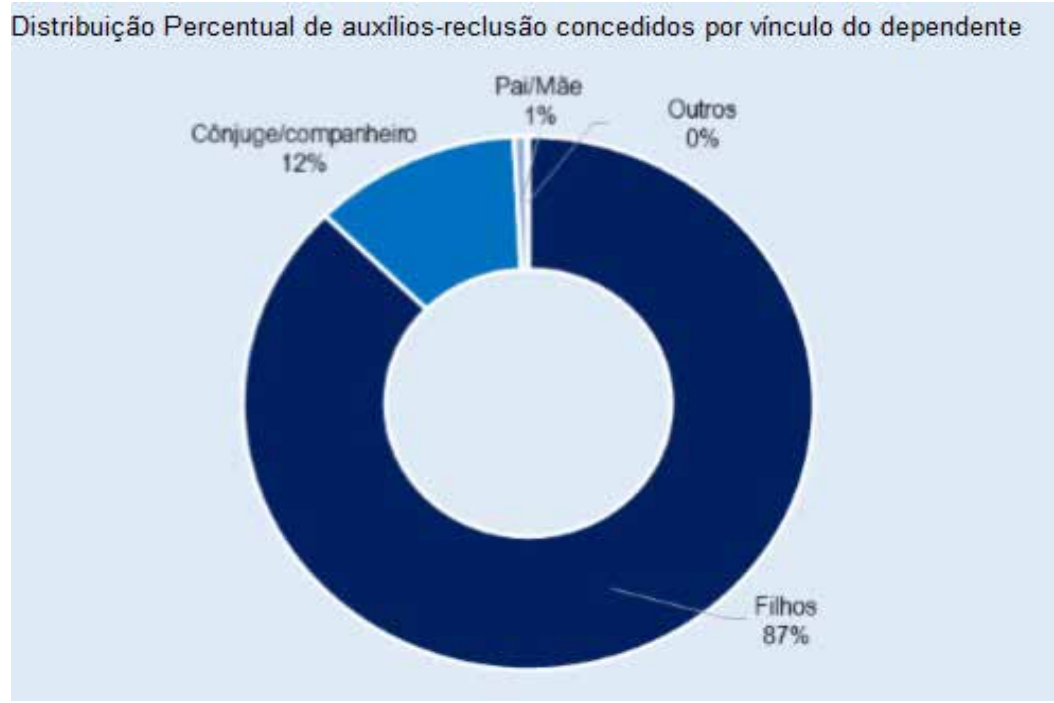

Fonte: LIMA NETA (2017).

Demonstra-se, portanto, que quem se beneficia do auxílio-reclusão são aqueles que mais precisam, ou seja, os filhos menores ou o cônjuge que ficam desamparados com a prisão do segurado. $O$ benefício garante o direito de os dependentes sobreviverem com um mínimo de dignidade.

O Infopen Mulheres, publicado em 2018, destaca que em junho de 2016 havia 42.355 mulheres presas no país. Dessa totalidade, apenas 3\% dos dependentes recebiam o auxílio-reclusão, em apenas 9 Estados da Federação (BRASIL, 2018b).

Diante da análise dos aspectos legais do auxílio-reclusão e os dados apresentados, verifica-se que o auxílio-reclusão exige o preenchimento de critérios para sua concessão, tendo caráter contributivo, proporcionando muitas vantagens para toda a sociedade.

\section{CONSIDERAÇÕES FINAIS}

O benefício previdenciário chamado auxílio-reclusão foi instituído em 1933, muitos anos antes da $\mathrm{CF} / 1988$, no entanto foi recepcionado por ela pois cumpria todos os requisitos para ser reconhecido como um direito constitucional. 
Previsto no artigo 201, IV da CF/88, o auxílio-reclusão é de suma importância para a comunidade brasileira, pois busca garantir a proteção da família do preso para que não fique desamparada economicamente enquanto perdurar a prisão, uma vez que proporciona à família do trabalhador que venha a ser preso o mínimo de renda para a garantia de sua subsistência, preservando, acima de tudo, a dignidade da pessoa humana.

Há vários critérios legais para que o benefício seja concedido; por exemplo, a comprovação da baixa renda do segurado. A partir de 2019, com a entrada em vigor da MP 871/2019, a qual alterou a Lei n. 8.213/91, foi modificado o acesso ao benefício, pois passaram a ser exigidos: a carência de 24 meses, a apresentação da declaração de cárcere a cada 3 meses e que o recluso esteja em regime fechado, não sendo mais concedido o benefíco aos reclusos em regime semiaberto.

Tais critérios limitam o acesso dos familiares do recluso ao benefício, o que faz com que fiquem desamparados financeiramente, pois, com o recebimento do referido auxílio, conseguiriam ter uma vida minimamente digna, custeando a base alimentar e educacional familiar até que o recluso estivesse novamente em liberdade.

Até o momento atual, tramita no Congresso Nacional a PEC 304/2013 que busca acabar com o auxílio-reclusão, substituindo-o por um amparo às vítimas. A extinção do benefício, entretanto, é inaceitável, haja vista ter caráter contributivo e não indenizatório, no qual o Estado não escolhe quem recebe ou não, pois, desde que sejam cumpridas as exigências previstas em lei, é um direito constitucional dos dependentes do segurado preso. A possível extinção do benefício com a PEC 304/13, se efetivada, trará muitos danos à sociedade, considerando que se a família ficar totalmente desamparada possivelmente incorrerá também na prática de crimes, tendo em vista que um lar com ausência da figura paterna ou materna, agregada com a baixa renda, deixará os jovens e crianças mais vulneráveis e excluídos da sociedade.

O argumento de que se gasta muito com auxílio-reclusão no país não é verídico, pois os dados do Infopen (BRASIL, 2016) demonstram que nem 10\% dos presos detidos em penitenciárias federais recebem o benefício. No mês de abril de 2018 foram pagos 48.755 benefícios de auxílio-reclusão, o que representa apenas $8,09 \%$, uma vez que no mesmo período se encontravam presas 602.217 pessoas, demonstrando, mais uma vez, que não são todos os presos que têm direito ao benefício, mas somente aqueles que conseguiram cumprir todos os requisitos legais.

Analisando os aspectos legais do benefício, pode-se considerar que o auxílio-reclusão é de extrema importância para a sociedade brasileira, porque, por meio do benefício, muitas famílias não ficam desassistidas, evitando que outras pessoas entrem para o "mundo do crime". É dever do Estado garantir a todos indiscriminadamente os direitos previstos no artigo 5o da CF/88, e quando o Estado falha nesta prestação de assistência oportuniza espaço para a criminalidade.

A concessão do auxílio-reclusão não deveria estar restrita a critérios objetivos como os que foram apresentados, mas estar vinculada a uma avaliação econômico-social da família dependente do preso, buscando um parecer social que apontasse quem realmente necessita do benefício, posto que os critérios utilizados atualmente excluem possíveis dependentes de segurados que precisam do benefício para garantir o mínimo para uma vida digna.

Ademais, a legislação brasileira demonstra que o auxílio-reclusão é um benefício previdenciário e não um benefício assistencial, sendo inconstitucional a sua extinção. A falta de informação por grande parte da população, todavia, abre cada vez mais espaço para ideias preconceituosas a respeito do tema. Pode-se assegurar que o benefício não tem o intuito de incentivar a prática de crimes, pois seu principal objetivo é amparar os dependentes, o qual é dever do Estado e da sociedade.

\section{REFERÊNCIAS}

ALVES, H. G. Auxílio reclusão: Direitos dos presos e de seus familiares. São Paulo: LTr, 2007.

ARAÚJO, A. S. B. O auxílio reclusão sob o aspecto (in)constitucional, 2012. Disponível em: http://dspace.bc.uepb.edu.br/jspui/ bitstream/123456789/3314/1/PDF\%20-\%20Alex\%20Sandro\%20Brito\%20Ara\%C3\%BAjo.pdf. Acesso em: 20 abr. 2019.

BRASIL. Código Civil de 2002. Lei no 10.406, de 10 de janeiro de 2002. In: Vade Mecum. 3. ed. Salvador, BA: Juspodivm, 2019a. p. 179-314.

BRASIL. Conselho Nacional de Justiça. Banco Nacional de Monitoramento de Prisões. 2018a. Disponível em: https://www.cnj. jus.br/sistema-carcerario/bnmp-2-0/. Acesso em: 29 jun. 2019. 
BRASIL. Constituição da República Federativa do Brasil de 1988. In: Vade Mecum. 3. ed. Salvador, BA: Juspodivm, 2019h. p. 2990.

BRASIL. Decreto no 22.872 de 29 de junho de 1933. Crêa o Instituto de Aposentadoria e Pensões dos Marítimos, regula o seu funcionamento e dá outras providências. Disponível em: www2.camara.leg.br/legin/fed/decret/1930-1939/decreto-22872-29-junho-1933-503513-publicacaooriginal-1-pe.html. Acesso em: 12 abr. 2019.

BRASIL. Decreto no 54 de 12 de setembro de 1934. Aprova o regulamento do Instituto de Aposentadoria e Pensões dos Bancários. Disponível em: https://www2.camara.leg.br/legin/fed/decret/1930-1939/decreto-54-12-setembro-1934-498226-publicacaooriginal-1-pe.html. Acesso em: 12 abr. 2019.

BRASIL. Decreto no 3.048 de 06 de maio de 1999. Aprova o Regulamento da Previdência Social, e dá outras providências. Disponível em: www.planalto.gov.br/ccivil_03/decreto/d3048.htm. Acesso em: 10 mar. 2019.

BRASIL. Decreto no 4.729 de 09 de junho de 2003. Altera dispositivos do Regulamento da Previdência Social, aprovado pelo Decreto no 3.048, de 6 de maio de 1999, e dá outras providências. Disponível em: http://www.planalto.gov.br/ccivil_03/decreto/2003/D4729.htm. Acesso em: 12 mar. 2019.

BRASIL. Emenda Constitucional no 20 de 15 de dezembro de 1998. Modifica o sistema de previdência social, estabelece normas de transição e dá outras providências. Disponível em: www.planalto.gov.br/ccivil_03/constituicao/emendas/emc/emc20.htm. Acesso em: 24 mar. 2019.

BRASIL. Lei Federal no 3.807 de 26 de agosto 1960. Dispõe sobre a Lei Orgânica da Previdência Social. Disponível em: www2. camara.leg.br/legin/fed/lei/1960-1969/lei-3807-26-agosto-1960-354492-norma-pl.html. Acesso em: 12 abr. 2019.

BRASIL. Lei Federal no. 8.213 de 24 de julho de 1991. Dispõe sobre os Planos de Benefícios da Previdência Social e dá outras providências. Disponível em: www.planalto.gov.br/ccivil_03/leis/L8213cons.htm. Acesso em: 09 mar. 2019.

BRASIL. Lei Federal no 13.846 de 18 de junho de 2019b. Institui o Programa Especial para Análise de Benefícios com Indícios de Irregularidade, o Programa de Revisão de Benefícios por Incapacidade, o Bônus de Desempenho Institucional por Análise de Benefícios com Indícios de Irregularidade do Monitoramento Operacional de Benefícios e o Bônus de Desempenho Institucional por Perícia Médica em Benefícios por Incapacidade; altera as Leis nos 6.015, de 31 de dezembro de 1973, 7.783, de 28 de junho de 1989, 8.112, de 11 de dezembro de 1990, 8.212, de 24 de julho de 1991, 8.213, de 24 de julho de $1991,8.742$, de 7 de dezembro de 1993, 9.620, de 2 de abril de 1998, 9.717, de 27 de novembro de 1998, 9.796, de 5 de maio de 1999, 10.855, de 10 de abril de 2004, 10.876, de 2 de junho de 2004, 10.887, de 18 de junho de 2004, 11.481, de 31 de maio de 2007, e 11.907, de 2 de fevereiro de 2009; e revoga dispositivo da Lei no 10.666, de 8 de maio de 2003 , e a Lei no 11.720 , de 20 de junho de 2008. Disponível em: http://www.planalto.gov.br/ccivil_03/_ato2019-2022/2019/lei/L13846.htm. Acesso em: 30 nov. 2019.

BRASIL. Medida Provisória no 871 de 18 de janeiro de 2019c. Institui o Programa Especial para Análise de Benefícios com Indícios de Irregularidade,... Disponível em: www.planalto.gov.br/ccivil_03/_Ato2019-2022/2019/Mpv/mpv871.htm. Acesso em: 20 abr. 2019.

BRASIL. Ministério da Economia. INSS - Instituto Nacional do Seguro Social. Portaria no 09 de 15 de janeiro de $2019 d$. Dispõe sobre o reajuste dos benefícios pagos pelo Instituto Nacional do Seguro Social - INSS e dos demais valores constantes do Regulamento da Previdência Social - RPS. Disponível em: www.in.gov.br/materia/-/asset_publisher/Kujrw0TZC2Mb/content/ id/59253484/do1-2019-01-16-portaria-n-9-de-15-de-janeiro-de-2019-59253472. Acesso em: 20 jun. 2019.

BRASIL. Ministério da Economia. INSS - Instituto Nacional do Seguro Social. Auxílio-Reclusão Urbano, 2017. Disponível em: www.inss.gov.br/beneficios/auxilio-reclusao-urbano. Acesso em: 20 jun. 2019.

BRASIL. Ministério da Justiça. Levantamento Nacional de Informações Penitenciárias - Infopen/2016. Disponível em: https:// www.gov.br/depen/pt-br/acesso-a-sistemas/sisdepen/infopen/Infopenjun2016.pdf/view. Acesso em: 29 jun. 2019.

BRASIL. Ministério da Justiça. Levantamento Nacional de Informações Penitenciárias Mulheres - Infopen/2018b. Disponível em: https://www.gov.br/depen/pt-br/acesso-a-sistemas/sisdepen/infopen-mulheres/infopenmulheres_arte_07-03-18.pdf/ view. Acesso em: 29 jun. 2019.

BRASIL. Ministério da Justiça. Levantamento Nacional de Informações Penitenciárias - Infopen/2019e. Disponível em: dados. mj.gov.br/dataset/infopen-levantamento-nacional-de-informacoes-penitenciarias. Acesso em: 29 jun. 2019.

BRASIL. Ministério da Previdência Social. INSS - Instituto Nacional do Seguro Social. Instrução Normativa no 77 de 21 de janeiro de 2015. Estabelece rotinas para agilizar e uniformizar o reconhecimento de direitos dos segurados e beneficiários da Previdência Social, com observância dos princípios estabelecidos no art. 37 da Constituição Federal de 1988. Disponível em: http://www.in.gov.br/materia/-/asset_publisher/Kujrw0TZC2Mb/content/id/32120879/do1-2015-01-22-instrucao-normativa-n-77-de-21-de-janeiro-de-2015-32120750. Acesso em: 21 jun. 2019.

BRASIL. Projeto de Emenda Constitucional no 304/2013a. Altera o inciso IV do art. 201 e acrescenta o inciso VI ao art. 203 da Constituição Federal, para extinguir o auxílio-reclusão e criar benefício para a vítima de crime. Disponível em: www.camara. gov.br/proposicoesWeb/prop_mostrarintegra?codteor=1123340\&filename=PEC+304/2013. Acesso em: 24 mar. 2019. 
BRASIL. Projeto de Emenda Constitucional no 06/2019f. Modifica o sistema de previdência social, estabelece regras de transição e disposições transitórias, e dá outras providências. Disponível em: www.camara.leg.br/proposicoesWeb/fichadetramitacao?idProposicao=2192459\&fichaAmigavel=nao. Acesso em: 23 jun. 2019.

BRASIL. Projeto de Emenda Constitucional no 09/2019g. Modifica o sistema de previdência social, estabelece regras de transição e disposições transitórias, e dá outras providências. Disponível em: www.camara.leg.br/proposicoesWeb/prop_mostrarintegra?codteor=1712459\&filename=PEC+6/2019. Acesso em: 23 jun. 2019.

BRASIL. Projeto de Lei no 5.671/2013b. Altera o artigo 80 da Lei no 8.213, de 24 de julho de 1991, para ratear o Auxílio-Reclusão aos dependentes de vítima de homicídio. Disponível em: www.camara.leg.br/proposicoesWeb/fichadetramitacao?idProposicao=578842. Acesso em: 23. jun. 2019.

BRASIL. Projeto de Lei no 8.313/2014. Altera a Lei no 8.213, de 24 de julho de 1991, para modificar o Auxílio-Reclusão e prever proteção aos dependentes de vítima de homicídio. Disponível em: www.camara.leg.br/proposicoesWeb/fichadetramitacao?idProposicao=858970. Acesso em: 23 jun. 2019.

BRASIL. Publicação do Parecer da Comissão de Seguridade Social e Família: de 28 de novembro de 2018c. Disponível em: www. camara.leg.br/proposicoesWeb/prop_mostrarintegra;jsessionid=7542386363512A3326C24C6CC0AB677F.proposicoesWebExterno1?codteor=1697212\&filename=Tramitacao-PL+5671/2013. Acesso em: 22 jun. 2019.

DIAS, E. R.; MACEDO, J. L. M. Curso de Direito Previdenciário. São Paulo: Método, 2010.

GOMES, Magno Federici; FERREIRA, Leandro José. Políticas Públicas e os Objetivos do Desenvolvimento Sustentável. Revista Direito e Desenvolvimento, João Pessoa, v. 9, n. 2, p. 155-178, ago./dez. 2018.

HORVATH JR., M. Direito Previdenciário. 10. ed. São Paulo: Quartier Latin, 2014.

IBRAHIM, F. Z. Curso de Direito Previdenciário. Rio de Janeiro: Impetus, 2008.

LIMA NETA, A. A. Informe de Previdência Social, Reflexões sobre o auxílio-reclusão, n. 10, v. 29, out. 2017: Disponível em: http://sa.previdencia.gov.br/site/2018/02/informe17.10.pdf. Acesso em: 21 jun. 2019.

MINAYO, M. C. de S. (org.). Pesquisa social. Teoria, método e criatividade. 18. ed. Petrópolis, RJ: Vozes, 2001.

PIOVESAN, F. Direitos humanos e o direito constitucional internacional. 4. ed. São Paulo: Max Limonad, 2000.

ROQUE, M. R. F. Auxílio-reclusão e PEC 304/2013: querem tirar o benefício de quem sequer o tem. Revista Liberdades, São Paulo, 19. ed. p. 26-34, maio/ago. 2015.

SARINGER, G. Mulheres que recebem auxílio-reclusão relatam preconceito. 2018. Disponível em: noticias.r7.com/economia/ mulheres-que-recebem-auxilio-reclusao-relatam-preconceito-11062018. Acesso em: 29 jun. 2019.

SILVA, J. J.; ANDRADE, G. D. Auxílio-reclusão e a EC 20/98: análise do requisito baixa renda á luz dos princípios constitucionais da seguridade social. Científic@, Goianésia, v. 2, n. 1, p. 52-73. 2014. 